Sociohistórica, $\mathrm{n}^{\circ}$ 41, e046, 1er. Semestre de 2018. ISSN 1852-1606

Universidad Nacional de La Plata.

Facultad de Humanidades y Ciencias de la Educación.

Centro de Investigaciones Socio Históricas

\title{
¿Una teoría marxista sobre los sindicatos? Balance con inventario para pensar las organizaciones obreras
}

\section{Luciana Zorzoli *}

* University of London. IdIHCS - Universidad Nacional de La Plata - CONICET, Argentina

Izorzoli@fahce.unlp.edu.ar

Cita recomendada: Zorzoli, L. (2018). ¿Una teoría marxista sobre los sindicatos? Balance con inventario para pensar las organizaciones obreras. Sociohistorica, 41, e046. https://doi.org/10.24215/18521606e046 


\title{
¿Una teoría marxista sobre los sindicatos? Balance con inventario para pensar las organizaciones obreras
}

\author{
A Marxist theory of trade unions? Balance plus inventory to think about workers' organizations \\ Luciana Zorzoli \\ University of London. IdIHCS - UNLP/CONICET, \\ Argentina \\ lzorzoli@fahce.unlp.edu.ar
}

\section{Resumen:}

Reconociendo que existe una variada serie de definiciones sobre qué son los sindicatos que han circulado asociadas a corrientes políticas o a destacados teóricos dentro del marxismo, este artículo se propone poner en discusión los desafíos que presenta una conceptualización no siempre integrada y consistente, recorriendo las obras de los autores clásicos y algunos de los aportes fundamentales del cuerpo teórico construido por el marxismo. Con ese objetivo, en el artículo se revisa cómo fue entendido el origen y las tareas de los sindicatos para Marx y Engels; cómo esas conceptualizaciones fueron apropiadas y reinterpretadas por los marxistas del siglo XX, presentando también las aproximaciones más actuales que permiten entrever una síntesis en los desarrollos teóricos sobre las organizaciones obreras. Se busca sobre todo realizar un balance a partir de un inventario que permita desplegar las herramientas que esta corriente posee para pensar las organizaciones obreras y dejar planteado un mapa de ruta para futuras indagaciones.

Palabras Clave: Teoría marxista, Sindicatos, Marx.

\section{Abstract:}

There are a series of definitions of what trade unions are that havebeenassociated with political currents or prominent theoreticians within Marxism.This article proposes to discuss the challenges presented by a conceptualization that hasnot always been integraland consistent, covering the works of the classic authors and some of the fundamental contributions of the theoretical body built by Marxism. With that objective in the article, we review how the origin and tasks of the unions were understood for Marx and Engels; how these conceptualizations were appropriate and reinterpreted by Marxists of the twentieth century, also presenting the most current approaches that allow us to glimpse a synthesis in the theoretical developments on worker organizations. The main objective is to make a balance from an inventory that allows to display the tools that this traditionpossesses in order to think about the workers' organizations and leave a road map for future inquiries.

KEYWORDS: Marxist theory, Trade unions, Marx.

\section{Consideraciones Generales ${ }^{1}$}

A lo largo de la historia moderna la búsqueda por contrarrestar el poder del capital dentro y fuera del lugar de trabajo ha dado lugar a distintas formas organizacionales con diversos objetivos, estabilizándose en el transcurso del siglo XX la formación de sindicatos. Gran parte de esos sindicatos fueron ganando reconocimiento estatal y patronal en occidente hasta conformar parte esencial de las relaciones laborales, especialmente después de 1945 cuando Europa se dispuso a aislar las tendencias radicales del movimiento obrero por la vía de, como lo denomina Geoff Eley, hacer la democracia “segura para el capitalismo”.

Aunque pueda resultar paradójico, dentro del marxismo, donde la clase obrera y sus formas de organización ocupan un lugar central teórica y políticamente, existen distintas acepciones sobre las organizaciones sindicales que han circulado asociadas a corrientes políticas, a destacados teóricos o a distintas “escuelas". Este artículo se propone poner en discusión los desafíos que presenta una conceptualización no siempre integrada 
y consistente, recorriendo las principales obras y autores que componen el cuerpo teórico del marxismo clásico y algunas de sus recuperaciones, especialmente la realizada por la tradición anglosajona. ${ }^{2}$

En esta exploración se atendieron los señalamientos hechos por Hobsbawm en su Historia del marxismo (1980) sobre los momentos significativos de producción teórica en su desarrollo como corriente primero europea y luego internacional (ver también Hobsbawm, 1983; Anderson, 1998). Para facilitar la lectura el artículo está dividido en tres secciones que abordan el origen y las tareas de los sindicatos para Marx y Engels; los sindicatos para algunos de los más destacados teóricos marxistas del siglo XX; y algunas de las aproximaciones actuales dentro de este campo que tienden a una síntesis teórica sobre las organizaciones obreras. Se presenta una última sección a modo de conclusiones que recapitulan lo elaborado.

En la primera sección se presentarán los escritos de los fundadores del marxismo que abarcan el período comprendido entre 1844 y 1895 , donde la explicación sobre la sociedad industrial en formación dio lugar a una reflexión que, aunque no fue sistemática, marcó los desarrollos posteriores. La segunda sección aborda las reflexiones que surgieron sobre este tema dentro del denominado "marxismo revolucionario" de comienzos del siglo XX. Las mismas orbitaron en torno a las ideas desarrolladas por los dirigentes bolcheviques (aunque no exclusivamente) en el contexto de la crisis de comienzo de siglo y el enfrentamiento bélico que Enzo Traverso llamó "la guerra civil europea" (2009). Integran este segundo momento los aportes de Rosa Luxemburgo, Lenin, León Trotsky y Antonio Gramsci, considerando que desde entonces y hasta mediados de los años sesenta la cuestión de los sindicatos se pensó dentro del marxismo en su relación con el partido obrero revolucionario, con la excepción del pensamiento de Gramsci que introdujo elementos novedosos. La tercera sección propuesta se aproxima al estudio del marxismo post años sesenta, cuando este ha perdido, como señala Daniel Bensaïd, coherencia interna como movimiento intelectual y político y la corriente se ha convertido en "un campo en disputa" sin una autoridad internacional ni una tradición única (2003). Son a su vez los años dorados de integración de la clase obrera en los países centrales, sacudidos sin embargo por crisis como el "invierno del descontento" inglés, el "mayo francés" o el "otoño caliente" italiano, donde la actividad sindical vivió una revitalización significativa que alentó el resurgir de la reflexión teórica sobre su accionar e importancia dentro del marxismo.

El artículo propone, en síntesis, un balance con inventario (siempre parcial) con el fin de indagar qué son los sindicatos para esta corriente y cómo pueden ser comprendidos en el marco de relaciones de producción capitalista.

\section{El origen y las tareas de los Sindicatos Para MarX y Engels}

Producto de que ni Karl Marx ni Friedrich Engels dejaron sistematizada una teoría sobre los sindicatos (como tampoco lo hicieron sobre las clases sociales o el Estado) y que, sin embargo, reflexiones sobre la naturaleza y el rol de los mismos aparecieron en sus obras a lo largo de un extenso período, es que algunos aspectos ganaron mayor circulación posterior y otros quedaron obscurecidos o sencillamente ignorados en las obras que inspiraron. Esto a pesar de que en el proceso mencionado ambos desarrollaron lo central de sus ideas y Marx elaboró la teoría del valor-trabajo, superando, por ejemplo, las teorías del salario provenientes de la economía clásica que habían acompañado sus ideas sobre los sindicatos en primer término (Landreth, Colander, y Rabasco 2006). Estos desarrollos no los llevaron, sin embargo, a una revisión teórica posterior y más madura sobre las asociaciones entre proletarios, asociaciones que tan importante rol habrían de tener al interior del marxismo y más allá de él, y que despertarían expectativas y debates que llegan hasta la actualidad.

Es precisamente esta carencia de una sistematización madura la que, como se verá en esta sección, permite sostener que en Marx y Engels no puede encontrarse una teoría sobre los sindicatos sino tan solo algunos elementos que se deducen tanto de algunos de sus escritos (especialmente los más coyunturales o políticos) como de la elaboración posterior de sus ideas fundamentales sobre el rol de la relación capital-trabajo. ¿Por qué revisar entonces sus escritos? En primer lugar porque es necesario examinar el argumento de aquellos 
que han intentado enhebrar sus posiciones (más estrictamente tres, que se corresponderían a tres períodos distintos de elaboración) entre los más de cincuenta años de variados escritos de ambos autores. En segundo lugar porque, a pesar de que no encontramos un corpus teórico desarrollado, sí es interesante analizar el conjunto de elementos que constituyen las primeras reflexiones consistentes con una perspectiva marxista en tanto estos establecen los principios sobre los que esta escuela de pensamiento fundó su comprensión de las organizaciones obreras. A continuación entonces se presenta una revisión sistemática de aquellos pasajes destacados de la obra de Marx y Engels sobre el tema, en una selección que, para facilitar su presentación, respeta un orden cronológico.

Comencemos por La condición de la clase obrera en Inglaterra escrito por Engels entre 1844 y 1849 (1968), que centra su atención en los sindicatos o asociaciones entre trabajadores por primera vez. Considerando las condiciones de vida de la clase obrera inglesa y aquello que los trabajadores hicieron para protegerse en el contexto de la gran expansión industrial, su análisis constituye la elaboración más destacada del autor sobre los sindicatos. Analizando las asociaciones entre trabajadores, Engels da cuenta del conflicto de clases y de la violencia con la que se expresa la clase trabajadora ante las penurias que enfrenta, pero también ante los actos que considera como una "traición" o una injusticia. Señala que la rebelión de los obreros contra la burguesía "comenzó poco después de los comienzos del desarrollo de la industria y a través de varias fases" siendo la primera "y la más brutal y estéril" la que tomó la forma criminal. Dice Engels que sólo cuando "los obreros se convencieron de la inutilidad de ese método", y dejaron de expresar su oposición a la dominación de la burguesía a través de la destrucción de máquinas, hubo espacio para que maduraran otras formas de asociación. Hasta entonces predominaron las acciones violentas que no modificaban el rumbo del proceso económico general y dejaban a los obreros aún más expuestos ante las acciones represivas. Como superación de esta primera respuesta es que surgen, según Engels, los sindicatos. ${ }^{3}$

Desde entonces todas las ramas industriales en expansión vieron el crecimiento de las asociaciones obreras buscando la protección colectiva "contra la tiranía y el abandono de la burguesía". Los objetivos que perseguían eran los de negociar con los empleadores, regular y defender el salario obrero en la búsqueda, según Engels, de una "escala universal de salarios" que no forzara a los trabajadores de algunas ramas o ante nuevas condiciones a ver descender el nivel de los mismos. Desde allí se desarrolló la historia de las asociaciones obreras, que era

... una larga serie de derrotas para los trabajadores, interrumpida por algunas aisladas victorias. Todos esos esfuerzos no pueden cambiar las leyes de la economía que indican que el salario se determina por la relación entre la oferta y la demanda en el mercado del trabajo. Estas asociaciones no tienen poder contra las grandes causas que influencian esas relaciones. En caso de crisis económica, la asociación se ve obligada a reducir ella misma el salario o disolverse completamente; y en el caso de un alza considerable de la demanda de fuerza de trabajo, no puede fijar el salario a un nivel más elevado que el que de terminaría de por sí misma la competencia entre capitalistas. Pero en lo que concierne a las causas de menor importancia, y cuyo efecto no es generalizado, ellas tienen poder. (Marx y Engels 1975, Vol. 4, pp. 502-506) ${ }^{4}$.

Algunos de los elementos que Engels generalizó en este primer escrito como objetivos de las asociaciones de trabajadores son considerados hasta hoy como constitutivos de los sindicatos modernos: la asociación voluntaria, la defensa mutua, la protección del salario y de los desempleados, la negociación y la disposición para enfrentar a los patrones en forma colectiva y organizada. Lo son también algunas de las limitaciones que menciona, centralmente la que indica que la lucha sindical no puede, por su naturaleza particular y limitada, modificar las condiciones generales de la relación capital-trabajo. Sin embargo gran parte de estos elementos estaban conectados con la nociones teóricas que Engels tenía de los sindicatos como “organizaciones naturales" y se relacionaban con su concepción sobre los mecanismos de fijación de salarios y las razones de sus fluctuaciones influenciada por las ideas de David Ricardo, que modificará posteriormente (Moses, 1990, p. 14).

Quizás sea el elemento más destacado de esta primera obra aquel por el cual se entiende que los sindicatos representan límites - aun cuando restringidos- al poder de la burguesía. Para Engels, si la competencia entre 
trabajadores en el mercado de trabajo era una condición para que la explotación exista, la asociación entre ellos para reducir esa competencia y negociar agrupados les permitía, cuanto menos, defenderse de la baja en el nivel de sus salarios. El efecto de esas luchas era limitado pero su valor radicaba en que expresaban "una protesta contra las condiciones inhumanas que la clase propietaria busca imponer a los proletarios". Eran una fuente de dignidad, expresión de la toma de conciencia sobre la sociedad de clases en la que reconocían su suerte común. Por eso el hecho de que los efectos de esas huelgas y luchas no pudieran extenderse en el tiempo ni permitieran modificar las condiciones generales de venta de la fuerza de trabajo para los obreros no implicaba para Engels su intrascendencia. Muy por el contrario, funcionaban según él como "verdaderas escuelas de guerra" que cumplían con la función de "preparar" a los trabajadores para enfrentamientos futuros. ${ }^{5}$

Esta comprensión del rol de las huelgas y los sindicatos como herramientas para que los trabajadores "maduraran" su enfrentamiento "inevitable" con el capital, trascendió en mucho La condición de la clase obrera en Inglaterra, e incluso opacó aportes posteriores, menos simplistas, que hicieron tanto Engels como Marx.

Forma parte también de esta primera etapa la polémica de Marx con Pierre-Joseph Proudhon, publicada bajo el título Miseria de la filosofía (1987) y donde la cuestión del antisindicalismo es abordada en el contexto del debate sobre la teoría del salario (especialmente en el último capítulo "Las huelgas y las colisiones de los obreros”). Allí Marx analizó la significación histórica de la lucha sindical ampliando las conclusiones que había presentado Engels. Indicaba que los sindicatos cumplían un rol en la preparación política del proletario en su "batalla futura" de clase contra clase y que actuaban con el doble objetivo de acabar con la competencia entre sí para poder "hacer una competencia general a los capitalistas" (Marx, 1987, pp. 119-20). Proponía, a diferencia de Engels, que incluso si la actividad asociada de los trabajadores no tuviera ningún efecto, si no cambiara en nada sustancial la relación entre trabajadores y patrones, tendría por seguro un efecto en el desarrollo capitalista pues, sostenía, existía un vínculo entre la introducción de maquinaría y la actividad colectiva de la clase obrera. La primera era para él una respuesta política de la burguesía -mediada por la tecnología - a los conflictos y las huelgas de los obreros, de modo que la actividad sindical tenía un impacto en la forma en que se producía el desarrollo de la industria. De este modo cuestionaba la noción de neutralidad asociada a las innovaciones tecnológicas, indicando que el capitalista usaba su poder de dirección en la producción como un "arma" contra las demandas obreras (Marx y Engels, 1987, p. 31). ${ }^{6}$

Junto con este hay un último trabajo que consideraremos parte de esta primera etapa de escritos ${ }^{7}$, cuya trascendencia es reconocida. Se trata de El Manifiesto Comunista, publicado por primera vez en enero de 1848, donde Marx y Engels explican esquemáticamente el desarrollo histórico del proletariado y las novedades implicadas para la clase oprimida con la industrialización. La lucha bajo estas novedosas condiciones tiene para ellos, más allá de éxitos siempre efímeros, un "verdadero fruto": el de expandir la unión de los proletarios para una lucha general contra la burguesía. Señalan que:

El proletariado pasa por diferentes fases de desarrollo. Con su nacimiento comienza su lucha con la burguesía. Al principio, la lucha es llevada adelante por obreros aislados; luego por los obreros de una misma fábrica, y al fin, por los obreros del mismo oficio de una localidad contra la burguesía que los explota directamente. Ellos dirigen sus ataques no contra el modo de producción burgués, sino contra los instrumentos de producción en sí mismos; destruyen las mercancías extranjeras que compiten con su trabajo, rompen en pedazos las máquinas, queman las fábricas y se esfuerzan en reconquistar la posición perdida del artesano de la Edad Media. En este estadio, los trabajadores forman aún una masa incoherente diseminada por todo el país y dividida por la mutua competencia.

Pero en el desarrollo de la industria no sólo aumenta el número de proletarios, sino que los concentra en masas, sus fuerzas aumentan y crece también la conciencia de ellas. Los variados intereses y las condiciones de existencia de los proletarios se igualan cada vez más, proporcionalmente a la medida en que la máquina borra toda diferencia en el trabajo y reduce casi en todas partes el salario a un mismo nivel inferior. La creciente competencia entre los burgueses y las crisis comerciales que ocasionan, hacen que el nivel de los salarios sea incluso más fluctuante. El constante perfeccionamiento de la máquina y su más rápido aún desarrollo, hacen a su vida más y más precaria, mientras que los choques entre obreros individuales y burgueses adquieren cada vez más el carácter de enfrentamientos entre dos clases. De allí, los obreros empiezan a formar asociaciones 
(tradeunions) contra los burgueses, se unen para mantener el nivel de sus salarios; fundan asociaciones permanentes para prever de antemano las revueltas ocasionales. Aquí y allá la resistencia estalla en sublevación.

De vez en cuanto los obreros triunfan; pero solo por un tiempo. El verdadero fruto de sus luchas reside, no en el resultado inmediato, sino en el crecimiento constante de la unión obrera (Marx y Engels, 1975, Vol. 6, pp. 492-493). ${ }^{8}$

Existe un extendido consenso sobre que provienen de esta primera etapa de escritos los elementos considerados claves en las ideas de Marx y Engels sobre los sindicatos. Esta idea está sin duda asociada a que en las obras posteriores de ambos autores la cuestión de los sindicatos ocupó siempre espacios más marginales y menos "optimistas". Contra esta idea Kenneth Lapides señala que este conjunto de trabajos clásicos constituye sólo una primera sección (y no la más decisiva para los propios autores) de las ocho que habría que diferenciar sobre este tema en la obra de los fundadores del marxismo para poder entender su desarrollo en un sentido pleno (ver Marx y Engels, 1987, Introducción, pp. ix-xx). Siguiendo a Lapides hay una segunda etapa de escritos en las "Historia de huelgas" que Marx escribió para el New York Daily Tribune entre 1853 y 1854, donde exploró la relación entre la ola de demandas salariales y la actividad sindical y los ciclos económicos, aunque sus conclusiones no fueron presentadas en una elaboración especial (Marx y Engels, 1987, pp. 41-56).

En los escritos que Lapides considera una tercera etapa reaparecen con mayor claridad las preguntas sobre el rol de los sindicatos asociadas a preguntas políticas que se formularon Marx y Engels en el período que va de 1859 a 1872, donde para ambos la elaboración teórica avanzó al calor de la creación de la Primera Internacional (fundada en 1864) como herramienta para la lucha socialista. Veamos como ejemplo las Instrucciones a los delegados del Consejo Central Provisional, un texto escrito por Marx para los delegados al Consejo Central Provisional enviados al I Congreso de la Asociación Internacional de los Trabajadores que tendría lugar en Septiembre de 1866, en Ginebra. En ellas retoma la genealogía que habían construido en la primer etapa de escritos, atendiendo al rol de los sindicatos y su pasado, avanza en delinear una crítica a su condición presente (por no haber aún "adquirido plena conciencia") y propone un "rumbo correcto", un plan político para los sindicatos. Dice lo siguiente:

(b) Su presente.

Ocupadas con demasiada frecuencia en las luchas locales e inmediatas contra el capital, las asociaciones obreras no han adquirido aún plena conciencia de su fuerza para actuar contra el sistema de la esclavitud asalariada en sí mismo. Por eso han estado demasiado al margen del movimiento social y político general. Sin embargo, últimamente se ha despertado en ellas la conciencia de su gran misión histórica, como lo prueban, por ejemplo, su participación en el movimiento político de Inglaterra; por la más amplia comprensión de su función en los Estados Unidos y por la siguiente resolución aprobada en la reciente conferencia de delegados de las asociaciones obreras realizada en Sheffield (...)

(c) Su porvenir.

Más allá de sus propósitos originales, deben ahora aprender a actuar deliberadamente como centros organizadores de la clase obrera atendiendo a los intereses generales de su completa emancipación. Deben ayudar a cada movimiento social y político que vaya en esta dirección. Considerándose y actuando como los campeones de toda la clase obrera, no pueden fallar en sumar a sus filas a los obreros no asociados. Deben cuidar celosamente los intereses de los obreros peor pagos, como los obreros agrícolas, que por las circunstancias excepcionales han quedado indefensos. Tienen que convencer al mundo que sus esfuerzos, lejos de ser estrechos y egoístas, buscan la emancipación de los millones de oprimidos (en «The general council of the First International, 1864-1872, Minutes» (1962). Moscú: Progress Publishers. Citado en la compilación de Lapides, Marx y Engels, 1987, pp. 64-65).

Es en este texto que aparece por primera vez la idea de que los sindicatos pueden, cerrándose sobre intereses particulares o "egoístas", desvincularse de los intereses generales de la clase obrera atendiendo sólo a demandas locales, particulares e inmediatas. Es una idea que rompe con la interpretación optimista y entiende que el destino de las asociaciones obreras no está inscripto en su carácter de clase sino en sus objetivos y orientación política. Esta misma idea aparece en otro texto de la época en el que Marx señala que "incluso en condiciones políticas favorables" la unidad obrera es indispensable y nada que no sea la unidad internacional de los proletarios puede garantizar el éxito a largo plazo, el fin de la sociedad de clases (Marx y Engels, 1987, pp. 65-67). 
Si hasta aquí primaba una lectura histórica que entendía a los sindicatos como un "paso" en la formación de una conciencia clasista de los trabajadores, ese paso aparecía cuestionado por la tensión abierta entre la lucha cotidiana frente a las consecuencias del régimen burgués y la lucha estratégica contra el capitalismo como orden social. Según J. Moses esto se debía a que Marx había avanzado en su comprensión y entendía "plenamente las tensiones emergentes de estas dos funciones de los sindicatos" (1990, p. 44), aunque la lectura de estos escritos no provee una evidencia tan clara como la que sostiene Moses que existe en ellos.

Lo cierto es que desde entonces aparecen tanto en los textos de Marx como en los de Engels juicios negativos, pesimistas, con quejas contra las acciones corporativas de los sindicatos y nociones despectivas como la de "minoría aristocrática", aplicada tanto a los sindicatos como a sus dirigentes. Una carta de Engels de Julio de 1871 a un socialista italiano sirve de muestra:

El movimiento sindical, entre todos los grandes, fuertes y ricos sindicatos, se ha vuelto más un obstáculo para el movimiento general que un instrumento de su progreso; y fuera de los sindicatos hay una inmensa masa de trabajadores en Londres que ha mantenido una considerable distancia del movimiento político durante varios años, y como resultado son muy ignorantes. Pero, por otro lado, también son libres de los múltiples prejuicios tradicionales de los sindicatos y las otras viejas sectas, y por lo tanto constituyen un excelente material con el que se puede trabajar (en «Karl Marx's Theory of Revolution»Vol. 2: The politics of Social Classes (1978). New York: Monthy Review. Citado en la compilación de Lapides, Marx y Engels, 1987 , p. 81).

Un informe de un discurso de Marx en Londres en la Conferencia de la Asociación Internacional de Trabajadores ese mismo año vuelve sobre el asunto cuando reniega de la decisión de los sindicatos de no construir una federación internacional, juzgando su accionar de la siguiente manera:

Los sindicatos son una minoría aristocrática. Los trabajadores más pobres no podrían unirse a ellos: la gran masa de trabajadores, impulsada por la evolución económica desde los pueblos hacia las ciudades, permanecen fuera de los sindicatos por mucho tiempo, y los más pobres de todos no ingresan nunca a ellos. (...) Los sindicatos por sí solos son impotentes - y seguirán siendo una minoría. Ellos no tienen a la masa de los proletarios detrás de ellos, mientras que la Internacional influye directamente sobre ellos; la Internacional no necesita de la organización de los sindicatos para ganar a los trabajadores - las ideas de la Internacional los inspiran directamente. Es el único sindicato que inspira plena confianza entre los trabajadores (Marx y Engels 1987, pp. 82-83 en «Werke» (1956). Berlin: Dietz Verlag. Traducido y citado por Lapides).

Se trata sin embargo de textos "periféricos" que no fueron concebidos para su publicación y que se vinculaban a batallas políticas en torno a la necesidad de crear, por y para el proletariado, una organización política internacionalista. Este hecho no puede ser negado y cuestiona a quienes sostienen que en ellos se presenta una "teoría sobre la aristocracia obrera" o sobre las "minorías aristocráticas" desarrollada por Marx. Como aquí lo entendemos, el término aristocracia es mucho más una derivación política que una conclusión sobre los sindicatos o sus dirigencias producto del análisis histórico o de la reflexión teórica, aunque el debate está sin dudas abierto (ver entre otros McLennan, 1981, pp. 262-63; Lapides, «Notas» en Marx y Engels, 1987, pp. 196-97; y Post, 2007).

En los escritos del período siguiente, entre 1863 y 1881, Marx sistematiza sus ideas sobre el salario y sobre el rol que tiene sobre este la acción "asociada" de los trabajadores, especialmente en la lucha por limitar la extensión de la jornada de trabajo y sus múltiples significaciones. Es el momento en que Marx presenta la teoría del valor-trabajo, la teoría del plusvalor y la teoría marxiana del dinero (Mandel, 1985, pp. 30-85) y son los años en los que se publica, en alemán, el primer tomo de El Capital (1867). Allí los sindicatos son sobre todo asociaciones de trabajadores que se protegen entre sí. Son una herramienta de la clase obrera para sostener el nivel del salario. Se pierde por ende el matiz que había aparecido en los escritos del tercer período sobre "las funciones" estratégicas de los sindicatos y sus tensiones. La explicación vuelve a girar sobre la productividad de esas batallas diarias contra el capital y prima su importancia en términos de defensa económica. Tanto Marx como Engels señalan que con ellas no se altera las condiciones que generan la asociación defensiva de los trabajadores (la existencia de clases sociales antagónicas donde la ley del salario "remachará cada día las cadenas que convierten al obrero en esclavo de su propio producto, monopolizado 
por el capitalista") e insisten en que expresan una resistencia que no es improductiva. Señala Engels en una explicación al respecto que:

La ley del salario, pues, no es una ley que actúa de manera inmutable y lineal. Hasta cierto límite no es inexorable. En determinado tiempo (exceptuando las grandes depresiones) existe para cada rama de la producción determinada amplitud de fluctuaciones, dentro de la cual la cuantía del salario puede experimentar cambios como resultado de la lucha entre las dos partes contendientes. El salario, en cada caso, se establece mediante una negociación, en el que quien más y mejor resiste tiene mayores posibilidades de sacar más de lo que le corresponde. Si el obrero aislado quiere regatear con el capitalista, es fácilmente vencido y se debe rendir a discreción; pero si los obreros de toda una rama de la producción forman una organización poderosa, reúnen un fondo que en caso de necesidad les permita resistir el combate con sus patronos, y gracias a ello son capaces de tratar con esos patronos de poder a poder, entonces y solo entonces podrán obtener la mísera limosna que, de acuerdo con el régimen económico vigente, se puede calificar de salario justo por una jornada justa.

La ley del salario no deja de regir en virtud de la lucha de las asociaciones. Al contrario, se cumple gracias a ella. Sin los medios de resistencia que dan las asociaciones, el obrero no percibiría ni siquiera lo que le corresponde según las leyes del sistema de trabajo asalariado. Es sólo ante la amenaza de las asociaciones frente a sus ojos que el capitalista decide pagar al obrero el valor de mercado de su fuerza de trabajo. ¿Queréis pruebas? Mirad el salario que se paga a los miembros de las grandes asociaciones y el que se abona en las infinitas industrias pequeñas de ese charco de profunda miseria que es el EastEnd londinense (The British Labor Movement. New York: International Publishers 1940, citado por Lapides en Marx y Engels, 1987, pp. 104-5).

Aquí el énfasis estaba puesto en la utilidad de las asociaciones, aunque de ello no se desprende que de la actividad en ellas hará madurar la conciencia obrera para enfrentar al capitalismo como forma de organización social. La ambigüedad se mantiene en los escritos de los tres períodos siguientes en los que Marx y Engels se ocupan de presentar una defensa del rol y la necesidad histórica de los sindicatos, esta vez contra Lasalle, Bakunin y nuevamente contra Proudhon, atacando al mismo tiempo a la "aristocracia obrera" y a los líderes sindicales ingleses, mientras daban cuenta de los avances de organización del proletariado norteamericano y de importantes huelgas en Europa (en especial la huelga de puertos en 1889 que marcó los escritos de Marx de entonces). 9

Se trata en primer lugar de una serie de cartas de ambos autores que abarcan el período 1868-1875 y que permiten comprender sus posiciones dentro de la lucha política en la Primera Internacional. En ellas aparece la distinción entre la lucha económica -aquellas acciones de sectores de la clase obrera realizadas para mejorar su salario o reducir su jornada laboral particular- y la lucha política, en la que se actúa en beneficio de la clase en su conjunto buscando robustecer los intereses generales del proletariado (ver por ejemplo Marx «Letter to Bolte» de 1871, publicada en Selected Correspondence, Moscú, Progress Publishers, 1965 y citado por Lapides en Marx y Engels, 1987, p. 133). En estos escritos, que se extienden en el caso de Marx hasta el momento de su muerte en 1883 y en el de Engels hasta 1895, pueden encontrarse severas críticas a las decisiones de los dirigentes sindicales, especialmente cuando estos se vinculan en Inglaterra a la corriente Liberal Laborista (conocida como Lib-labs) y renuncian a la organización de un partido político clasista. ${ }^{10}$

Aunque retoman los elementos críticos de los períodos previos, en esta última etapa ni Marx ni Engels revisan las aseveraciones realizadas en las obras de mayor envergadura, ni arriesgan generalizaciones sobre los sindicatos y sus dirigentes. Entendemos que quedan como impresiones eminentemente políticas, circunstanciales y no como una "teoría", lo que hace controversial la afirmación de Lapides sobre que existen elementos que confirman que podemos hablar de una "teoría de los sindicatos". Los elementos que Lapides destaca no son convincentes; señala en primer lugar la idea de Engels de que los sindicatos son un resultado "inevitable" del crecimiento de la industria y de la clase obrera, logrando para la misma al menos una protección contra los abusos del capital. En segundo lugar afirma que Marx y Engels en el debate contra las concepciones dominantes entonces demostraron la "necesidad histórica" de los sindicatos y en tercer y último lugar, que las huelgas y organizaciones obreras de por sí son insuficientes para revertir la situación de la clase obrera de modo estructural (Introducción, Marx y Engels, 1987, p., xix). 
Desde el punto de vista adoptado en este artículo, este conjunto de elementos y textos heterogéneos tanto por su producción como en los contextos en que fueron publicados no son suficientes, a pesar de los esfuerzos por darles coherencia que hizo Lapides, para hablar de una teoría general de los sindicatos en Marx y Engels. No nos parece tampoco que sus aportes puedan ordenarse como optimistas y pesimistas, pero volveremos sobre esto en el balance propuesto al final.

Veamos ahora qué pasó inmediatamente después con la herencia que los autores dejaron, una herencia cuya recepción se dio, en primera instancia, en medio de la convulsionada situación europea de comienzos del siglo XX.

\section{LOS SINDICATOS PARA LOS MARXISTAS DEL SIGLO XX}

Siguiendo las secciones que se han propuesto al comienzo de este artículo se abordará a continuación cómo las ideas formativas de Marx y Engels fueron apropiadas por Lenin, Luxemburgo y Trotsky -considerándolos con sus matices como a un mismo grupo- y por Gramsci, que se diferenció en importantes aspectos de la lectura hecha por los tres primeros. Nos detendremos solo brevemente en ellos porque, como se verá, los desarrollos que hicieron sobre los sindicatos giraron en mayor medida en torno a dos cuestiones que no son centrales en esta indagación: la cuestión de la maduración o conquista de una conciencia de clase revolucionaria y la relación del sindicato con el partido comunista en miras a la toma del poder y el establecimiento de un Estado de transición al comunismo, con reflexiones solo marginales sobre la aparición de un sindicalismo no revolucionario organizado en torno a una política reformista de objetivos "particularistas".

Tomemos para comenzar las ideas de Lenin sobre los sindicatos, ideas que están inevitablemente asociadas a sus ideas generales sobre la necesidad histórica de la revolución socialista y la centralidad que este asignó a lo largo de su praxis revolucionaria a la política. Como señala Kelly (2007), es en el ¿Qué hacer? de 1902 donde se encuentran las primeras ideas de Lenin sobre las organizaciones obreras. Estas han dado lugar a una infatigable controversia no sólo en el momento de su producción y en los años subsiguientes sino a lo largo de todo el siglo XX, en el que el pensamiento de Lenin fue el organizador de corrientes políticas que disputaron su legado.

Se considera aquí válido el argumento de Kelly que sostiene que en el ¿Qué hacer? y en sus escritos posteriores Lenin no tuvo una inamovible visión de los sindicatos como organizaciones estáticamente limitadas -reformistas- cuyo rol estaría predeterminado por las condiciones que les dieron origen, sino que lo guió la búsqueda de diferenciar entre reformismo y revolución, la misma que lo llevó a crear el partido bolchevique en fecha tan temprana como 1904, o a renunciar a la Segunda Internacional ante la claudicación de muchos de sus miembros en el escenario de la Primera Guerra Mundial. Lo que Lenin implicaba, dice Kelly:

no era que los sindicatos eran organizaciones traidoras que fracasaban en promover los intereses de los trabajadores, sino que éstos, persiguiendo la lucha económica y las reformas parlamentarias se involucraban en un tipo de política que era completamente compatible con el gobierno social de la burguesía (1988, p. 32).

A partir de este punto el eje sobre el que giró el aporte de Lenin no fueron "los sindicatos" como objeto, sino que se orientó a discutir sus vínculos con la política revolucionaria y especialmente con el partido.

Emparentado con esta obra debe entenderse el aporte de Rosa Luxemburgo. Luxemburgo compartía elementos centrales de la concepción teórica y política general de Lenin, y sus abordajes del tema también estaban marcados por las "necesidades" de la política (Cliff, 1983). Su concepción, presentada en el libro de 1906 La huelga de masas (1970), estuvo articulada principalmente contra los dirigentes sindicales alemanes y contra todo el pensamiento reformista en el seno del movimiento obrero a partir de la experiencia de la revolución rusa de 1905. Luxemburgo desarrolló en La huelga de masas un modelo que vinculó "algunas 
actividades huelguísticas" - no todas- con el desarrollo de la conciencia de clase y le asignó en este marco un rol determinante al partido revolucionario en su evolución posterior (ver Kelly, 1988, p. 37). Su reflexión no abordó sin embargo las otras huelgas, las que podríamos considerar "regulares" o "no revolucionarias", y menos aún la estructura de los sindicatos y sus direcciones más allá de la diferenciación política entre quienes defienden posiciones reformistas y quienes buscan la revolución social.

La visión de Trotsky también se formó en estos primeros años del siglo XX vinculada a las experiencias revolucionarias rusas de 1905 y 1917, pero se sistematizó décadas después, en sus escritos sobre la situación política en Inglaterra o alrededor de las implicancias políticas de su Programa de Transición de 1938 (2007), todos ellos escritos cuando se encontraba en el exilio en México, marginado por la fuerza del proceso político europeo. En esos escritos Trotsky retomó a Lenin y a Luxemburgo pero acentuó dos elementos que son propios de su obra: la caracterización de la "madurez del capitalismo imperialista" y la denuncia sobre el rol de la "burocracia sindical" en el sostenimiento de un régimen que consideraba perimido. La dirigencia sindical es en su obra una "burocracia" sostenedora del régimen de opresión y los sindicatos son "los culpables" de las derrotas de la clase obrera, pero no porque no tuvieran una función positiva que cumplir como instituciones de la clase trabajadora -la visión de Trotsky sobre esto puede verse en el mismo Programa de Transiciónsino porque se encontraban "entregados a una política de colaboración de clases e incluso, sufriendo una estatización" (Trotsky, 1973). En esta lectura prima la idea de la "degeneración de los sindicatos" de su "adaptación" al régimen burgués, pero no como indicador de alguna función o naturaleza de los mismos en tanto instituciones sino como alteración de sí mismos, como su descomposición (Kelly 1988, pp. 40-51; ver también Santella, 2014, p. 9).

En estas tres visiones cobró relevancia la "necesidad" de actuar "contra la burocracia sindical", que se entendía estaba empeñada en embarcar a los trabajadores en el reformismo y en aniquilar la democracia sindical en los espacios de producción. Con esto aparecieron en el marxismo los primeros esbozos de análisis sobre la relación de integración de los sindicatos con el Estado (algo que abordó Trotsky) y la pregunta sobre cómo debía ser la relación entre la organización sindical y el partido en el proceso de transformación revolucionaria del proletariado. A pesar de los elementos de continuidad con lo desarrollado por Marx y Engels, tanto Lenin, como Luxemburgo y Trotsky reservaron un sesgo positivo para "los verdaderos sindicatos" y vieron en el rumbo tomado por las organizaciones obreras a comienzos de siglo una desviación de las que serían sus "verdaderas funciones" e intereses. Es en este punto donde el pensamiento de Antonio Gramsci aportó una matriz diferente, legando a la generación siguiente una comprensión que entendemos como superadora. ${ }^{11}$

La mayor parte de esos escritos de Gramsci pertenecen a los años veinte y fueron publicados en L'Ordine Nuevo, el periódico del que era editor. En sus análisis cobran relevancia las organizaciones obreras y especialmente los "Consejos de Fábrica" que se habían extendido en Italia con la ola de conflictos del final de la Primera Guerra Mundial y que tendrán un peso decisivo en el pensamiento de Gramsci sobre los sindicatos "comparando y contrastando unos con otros" (Kelly, 1988, p. 54). Las características de las organizaciones que surgieron al calor del "Bienio Rojo" eran en gran medida opuestas a las de los sindicatos; en ellas había democracia directa, revocabilidad de la representación, unificación de trabajadores sindicalizados y no sindicalizados, predisposición a la ruptura del "orden" de la producción, rasgos que ya no presentaban los sindicatos institucionalizados de Europa (Mandel, 1977). Por eso Gramsci les dedicó gran parte de su reflexión y dirigió a esos "Consejos” sus planes políticos como teórico revolucionario (Haidar, 2010).

Es a partir de ese contraste entre los Consejos y los sindicatos que se alimenta la reflexión de Gramsci sobre los últimos. Veamos por ejemplo lo que dice en "La conquista del Estado", de julio de 1919, en el que señala que hay que entender a los sindicatos desde una perspectiva histórica como parte de la sociedad capitalista, relativizando la decisión subjetiva de los obreros en la creación de sus organizaciones y destacando el poder como organizador social del capital. 
El desarrollo de las instituciones proletarias y del movimiento proletario en general no fue un desarrollo autónomo, ni obedeció a las leyes inherentes de la vida ni de la experiencia histórica de la clase trabajadora explotada. Las leyes de la historia fueron dictadas por las clases propietarias organizadas en el Estado. El Estado ha sido siempre el protagonista de la historia, porque en sus organismos reside el poder de la clase propietaria, que en el Estado se disciplinan y forman una unidad, por encima de las discrepancias y de las luchas engendradas por la competencia, con el objetivo de mantener intacta su situación de privilegio en la fase suprema de aquella misma competencia” (Gramsci, 1919, p. 1).

Es justamente por las condiciones de su propia existencia que los trabajadores no desarrollaron en forma libre sus organizaciones y que las mismas no tomaron formas organizacionales “independientes" o sujetas a cuestiones ideológicas, culturales o de otro tipo. Su forma, por el contrario, fue determinada por una ley externa y "bajo la formidable presión de los hechos y las coerciones de la competencia capitalista", según Gramsci. Destaca así que los sindicatos asumieron como propia la forma en que se organizó la producción capitalista, reflejando la división del trabajo existente en la división organizacional de los trabajadores, algo que condicionaba los intereses - cuanto menos básicos- que representarían. Esto indica que los sindicatos fueron constituidos como organizaciones proletarias pero no a partir de la posición de clase de quienes los fundaban, sino en concordancia con los lugares circunstanciales que estos tenían como vendedores de fuerza de trabajo, en relación con su empleo específico. No era un elemento nuevo en la consideración sobre este tema que esta lógica organizacional implicaba aspectos problemáticos, en tanto que excluía de la organización a otros sectores de la clase obrera con empleos domiciliarios, temporales o trabajos más precarios, algo que ya había señalado Engels aunque había quedado como un elemento más bien marginal.

Para Gramsci esto no implicaba que los sindicatos fueran una respuesta parcial o "inadecuada" a las necesidades históricas de la clase obrera -como se había esbozado-, o que estuvieran desviados de su verdadera función. Lo que Gramsci señaló es que el movimiento sindical y los sindicatos no podían ser, por estas razones de su constitución, el "verdadero intérprete del marxismo" como lo pareció en algún momento. Los sindicatos, decía, "no están muertos" y como nacieron como función de la libre competencia "deben continuar existiendo hasta la supresión de todo residuo de competencia, hasta la completa supresión de las clases y de los partidos, hasta la fusión de las dictaduras proletarias nacionales en la Internacional comunista" (Gramsci, 1919, p. 4), pero no pueden reemplazar al partido revolucionario ni a los comunistas, que no deben abandonarse al curso de los acontecimientos determinados por las leyes de la sociedad burguesa, sino que deben actuar de acuerdo con la "expectación crítica" de quienes quieren fundar un nuevo orden social.

El marxismo había pensado hasta entonces a los sindicatos como pieza asociada al partido revolucionario y a su estrategia política. Gramsci desarmó esa asociación, o relativizó su importancia, sosteniendo que los sindicatos no se habían constituido para representar los intereses de la clase de conjunto y que su función había sido moldeada por condiciones que dificultaban que ese fuera su desarrollo.

Kelly señala además que, a diferencia de los otros referentes del marxismo -especialmente de Trotsky-, Gramsci abordó la cuestión de las dirigencias sindicales y explicó el conservadurismo de los dirigentes no por sus vicios "aristocráticos", ni por posiciones personales privilegiadas (salario, condiciones de empleo, expectativas, etc.), sino por las determinaciones impuestas por esa función asumida por los sindicados. Esto es, por el objetivo de buscar mejoras en los términos y condiciones de la venta de fuerza de trabajo de sus miembros tanto por la vía del conflicto como "obligando al empleador a reconocer la legalidad de sus acuerdos con los trabajadores, una legalidad que es condicional a su confianza en la solvencia de los sindicatos y en sus capacidades de hacer respetar las obligaciones convenidas a las masas obreras" (Antonio Gramsci: selections from political writings, 1910-1920, Lawrence \& Wishart, 1977, citado por Kelly en, 1988, p. 56).

Asumiendo que para poder negociar los términos de venta de la fuerza de trabajo los sindicatos debían aceptar y someterse a una determinada legalidad impuesta por los patrones, Gramsci reconocía la importancia que tuvo en el desarrollo del sindicalismo moderno la negociación con su red de instituciones, leyes, y procedimientos. Destacó, como no se había hecho hasta entonces desde el marxismo, que la acción organizada dentro de esa "legalidad" determinó en gran medida las formas prósperas del sindicalismo y sus límites, sin 
sostener por eso la idea de que esas formas y objetivos eran inmutables o estaban condenados a perdurar en el tiempo. Justamente por eso Gramsci continuó sosteniendo que era necesario que el partido revolucionario realizara "una labor preparatoria de sistematización y de propaganda" entre los trabajadores, y que impulsara nuevas instituciones proletarias (los Consejos de Fábrica), estimulando la aparición de nuevos dirigentes y desnaturalizando la organización existente.

Pero no fue sino en el contexto de un resurgir de la conflictividad de la clase obrera, después de la derrota del fascismo en Europa y el establecimiento de los Estados de bienestar de la postguerra, que estas ideas volvieron a ser discutidas. Estas exploraciones no estuvieron vinculadas a los partidos comunistas, que cristalizaron en organizaciones dogmáticas y autoritarias, sino que se desarrollaron en una zona de contacto entre el conocimiento académico y la política de la "nueva izquierda". Por esa razón no sólo retomaron la tradición teórica del marxismo, sino que también construyeron una serie de batallas contra los estudios sobre los sindicatos y la clase obrera que habían predominado en los espacios académicos, especialmente en el mundo anglosajón, formando lo que Rosemary Aris llamó una "escuela revolucionaria" contra los estudios clásicos del trabajo (1998).

La anteúltima sección de este artículo partirá de los aportes de esta escuela, destacando la obra Richard Hyman en tanto que sus elaboraciones, basadas en una relectura de estos elementos de la obra de Gramsci que se han destacado en esta sección, permiten avanzar en la elaboración de este "inventario" de ideas sobre los sindicatos.

\section{APORTES PARA UNA SÍNTESIS}

Mientras dentro de las corrientes del marxismo se debatía -aunque no como tema central- la cuestión de los sindicatos, las Ciencias Sociales avanzaban en su estudio y comprensión de los mismos, con aportes tan tempranos como los de Beatrice and Sidney Webb. ${ }^{12}$ La aproximación que predominó en esos estudios fue sin embargo una aproximación descriptiva-normativa, que buscaba captar las reglas y normas de las relaciones industriales para evitar el conflicto, algo que para el marxismo no es más que una utopía de carácter reaccionario y que necesariamente obscurece la comprensión sobre qué son los sindicatos, amén del debate sobre quépueden ser.

Como reacción frente a ellos surgió en gran medida la "escuela revolucionaria” inglesa, que afirmó al marxismo dentro de los estudios de las relaciones laborales. ${ }^{13}$ Allí se destacó el aporte de Richard Hyman -cuya obra hemos analizado en parte en un trabajo previo- ${ }^{14}$ y desde allí su nombre, junto con el de Braverman, fueron identificados en el mundo anglosajón tanto con el esfuerzo de dar cuenta de la importancia creciente de las formas de administración del conflicto capital-trabajo, como de polemizar sobre el lugar que estas formas fueron tomando en el discurso académico-político de las relaciones industriales y el management (Wood, 1976).

¿Cuáles eran las preguntas que se hacían en los años sesenta y setenta frente a los sindicatos cuando el capitalismo de los países centrales transitaba su fase de expansión "dorada"? Se trató de años, como dice Beverly Silver, donde primó un proceso de desradicalización del conflicto laboral -comparándolo con la primera mitad del siglo XX- y las relaciones industriales se estabilizaron mayoritariamente a través de los acuerdos colectivos (collectivebargaining), algo que no impidió que los sindicatos tuvieran gran visibilidad y peso político ni hizo que faltaran olas de conflictos y huelgas de gran trascendencia. Los temas más destacados fueron, revisando aquellas obras, los objetivos sindicales y las funciones "básicas" de los sindicatos, las razones de la afiliación sindical y del crecimiento de la densidad sindical en determinados sectores económicos hasta entonces no había sido un tema de indagación el retroceso de la afiliación sindical, algo que atrajo cada vez más interés por el crecimiento de este fenómeno desde los años ochenta-. También fueron centrales los debates sobre las características y limitaciones de los objetivos sindicales y las formas de organización sindical 
(la administración de las organizaciones, la existencia de dirigentes que trabajan "tiempo completo" en el sindicato, etc.). Asociados a estos objetivos y formas de organización la cuestión de la democracia sindical y sus limitaciones operativas fue abordada, aunque mayoritariamente en el marco de los debates sobre eficacia y democracia sindical. Hyman destacó asimismo el rol de las funciones "subsidiarias" de las organizaciones obreras (aquellas sociales, recreacionales, de asistencia, etc.) distanciándose por ejemplo de la definición dada por Flanders y los miembros de la Oxford School que, derivada de la tradicional definición de los Webbs, indicaban que eran básica y esencialmente agencias para la negociación. ${ }^{15}$

La representación en el lugar de trabajo y su importancia creciente durante aquellos años generó también una renovación significativa en los estudios laborales. La influencia y presiones sobre esa representación tanto del Estado, del management, del sindicato y de los trabajadores de base mismos; el rol de los delegados en la educación sindical y las tensiones entre representación formal e informal fueron algunos de los temas abordados (Hyman presentó una síntesis de estos debates y algunos problemas teóricos vinculados a ellos en "The politics of workplace trade unionism: recent tendencies and some problems for theory", de 1979).

A la reflexión sobre estos temas se sumaron los estudios de los procesos de control (formales e informales) que viven las y los trabajadores y los procesos de resistencia que estos impulsan. ${ }^{16}$ En continuidad con la propuesta de Gramsci, además, se acepta generalmente que los sindicatos se formaron como parte de esos procesos de resistencia, pero no como organizaciones de clase en su sentido estrictosino como agrupamientos de sectores o fracciones de la clase, definidos -las más de las veces- por identificaciones que reflejan la forma en que el capital organizó u organiza el trabajo. Así entendidos, los sindicatos son un producto de una de las formas de poder con las que cuentan los vendedores de fuerza de trabajo ante la dominación del capital: el poder "asociativo". Esta categoría ha sido señalada por Erik Olin Wright $(1997,2000)$ para quien los trabajadores poseen distintos tipos de poder para contrarrestar esa dominación capitalista, el asociativo que mencionamos y el estructural, que surge de la posición de los trabajadores en el sistema económico, ya sea el que se deriva del mercado de trabajo -que Silver ha denominado "poder de negociación en el mercado de trabajo" - o el que surge de la posición de un grupo determinado de trabajadores en el proceso de trabajo mismo (Womack, 2007).

Junto con esto, se acepta que dentro de la estructura de poder de las asociaciones obreras debe distinguirse el poder del sindicato sobre sus miembros del poder del sindicato para sus miembros, algo que remite necesariamente a las reflexiones sobre los problemas de representación, democracia e intereses en estas organizaciones. Esto porque en tanto el sindicato es reconocido por el Estado y la burguesía como una organización integrante de las relaciones laborales "normales", surge la posibilidad de que utilice al menos parte de su poder para servir a objetivos propios -su propia estabilidad por ejemplo- o externos - tales como movilizar recursos para un partido político-, distanciándose al menos parcialmente de los intereses colectivos que le dieron origen. Tenerlo en cuenta no implica, claro está, simplificar las relaciones internas de un sindicato y mucho menos verlas como unidireccionales o verticales, negando los complejos procesos de toma de decisiones y las presiones a las que están expuestos los sindicatos $-\mathrm{y}$ todos los sectores que los integran- o las razones sociohistóricas que pueden llevar al sindicato a integrarse más o menos al sistema de control sobre los trabajadores. Es en ese marco que desde el marxismo puede pensarse la cuestión de la burocratización de la dirigencia sindical contra toda presentación institucionalista, conspirativa o mecanicista. ${ }^{17}$

La importancia de la cuestión democrática también es un tema de recurrente interés en especial frente a nuevas formas de organización, o confrontaciones entre sindicatos establecidos y organizaciones más o menos espontáneas de grupos de asalariados, muchas veces indagando en la compleja dinámica que existe entre las prácticas democráticas en los lugares de trabajo y la institucionalización del poder que deriva de ellas en la estructura sindical (algunos abordajes recientes sobre este tema en estudios sobre el caso argentino en Lenguita y Varela, 2010; Zorzoli, 2014; Atzeni, 2016. Ver también Darlington, 1994, 2002; Moody, 2014; Ness, 2014; Burgmann, 2016). Se entiende que esas prácticas no son meramente formas sino que contienen y alimentan diferencias sobre los objetivos sindicales que tampoco pueden pensarse desvinculados 
de la dominación del capital -no sólo sobre las dirigencias, sino y sobre todo, sobre las y los asalariados de conjunto-. Vale volver a Hyman sobre este aspecto, pues él señaló, con una claridad poco común, que los mecanismos y las influencias en los procesos de conformación de objetivos y toma de decisiones sindicales están inscriptos en entornos muy singulares, especialmente desde los años cincuenta donde una fuente central de estabilidad para las organizaciones obreras ha sido la negociación formalizada.

El resultado de aquellos debates y de las elaboraciones posteriores no resultó, sin embargo, en una sistematización teórica mayor. ${ }^{18}$ Esto en parte porque la perspectiva adoptada recaía en posiciones más propias de cierto estructuralismo -como puede verse con Hyman-o porque persistían identificaciones políticas que recuperaban a los "clásicos" desconociendo todo desarrollo posterior.

Un ejemplo de esto puede verse en el breve artículo de Perry Anderson "The Limits and Possibilities of Trade Union Action", publicado por primera vez en 1967. Sostenedor de las ideas del Lenin del ¿Qué hacer?,Anderson retrató a los sindicatos (centrándose en los británicos) como "cunas de reformismo" e hizo un decálogo muy cuestionable de las supuestas limitaciones de la acción sindical, contraponiéndolas a las ilimitadas posibilidades que tenía el partido revolucionario (1967). Su trabajo, pese a lo rudimentario de los argumentos, tuvo gran circulación y varias traducciones, demostrando que dentro del marxismo no había -aun en los albores de los años setenta- un campo común de reflexión sobre la acción colectiva de la clase obrera ni sobre sus organizaciones.

Con contadas excepciones (entre ellas Kelly) esta situación de fines de los 70 seguía siendo similar a principios de este siglo. Quizás por eso Marcel van der Linden retomó recientemente parte de esos problemas en su libro Workers of the World; Essays toward a global history of labor (2008). Partiendo de una definición amplia de trabajadores y de un estudio basado en el largo plazo, van der Linden señaló que los sindicatos son una de las formas de resistencia frente al capital y que quienes se unen a estos tienen al menos dos preocupaciones: sus salarios y las formas de consumo de la fuerza de trabajo que les ha comprado / que le han vendido al empleador. En este marco, sostiene, se organizan los sindicatos que, para ser tales, tienen que ser capaces cuanto menos de amenazar con la posibilidad de realizar una huelga (2008, p. 220). ${ }^{19}$

Atento a la variedad de sindicatos presentes en la historia, van der Linden propuso una tipología (resumida en un esquema reproducido a continuación) que señala la existencia de tres tipos de organizaciones (sindicatos organizados principalmente para la huelga, sindicatos sin la huelga como objetivo/recurso principal, sindicatos que no se organizan para poder hacer huelgas) bajo dos categorías generales: "autónomos" y "heterónomos".

\begin{tabular}{|l|l|l|}
\hline & Autónomos & Heterónomos \\
\hline $\begin{array}{l}\text { Sindicato que se dedica } \\
\text { principalmente a organizar } \\
\text { huelgas }\end{array}$ & $\begin{array}{l}\text { Sindicalismo revolucionario; } \\
\text { Sindicatos "hongo"* }\end{array}$ & - \\
\hline $\begin{array}{l}\text { Sindicato que no se dedica } \\
\text { principalmente a organizar } \\
\text { huelgas }\end{array}$ & $\begin{array}{l}\text { Sociedades artesanales; } \\
\text { Sindicatos de negociación }\end{array}$ & $\begin{array}{l}\text { Sindicatos } \\
\text { Autocráticos; } \\
\text { "Rackets"** }\end{array}$ \\
\hline $\begin{array}{l}\text { Sindicatos que no se } \\
\text { organizan para poder hacer } \\
\text { huelgas }\end{array}$ & Sindicalismo \\
\hline & amarillo \\
\hline
\end{tabular}

$\left({ }^{*}\right.$ En el mundo anglosajón se denomina de ese modo a los sindicatos que surgen para comenzar una huelga o durante su desarrollo y que se desorganizan rápidamente después de las mismas. ** Sindicatos creados por organizaciones criminales para beneficiarse de su posible rol en las relaciones laborales, regulados mayormente por el uso de la violencia.Tomado de Van der Linden, 2008, p. 225).

Lamentablemente la síntesis que propone van der Linden se realiza dentro del marxismo pero sin recuperar a los autores clásicos en forma explícita, y aunque retoma muchos de los temas elaborados previamente, no 
contiene una genealogía que nos permita historiar la cuestión de los sindicatos ni ubicar su aporte en relación con los demás. Además, su elaboración, por partir de una taxonomía, corre el riesgo de perder especificidad y deslizarse a posiciones ahistóricas. Esto no quiere decir que él, como lo había hecho Hyman a fines de los años setenta, no haya presentado una síntesis interesante dentro del marxismo sobre el tema, pero sí que lamentablemente no logra ocupar el lugar vacante de una sistematización mayor sobre las organizaciones obreras.

\section{A MODO DE BALANCE}

Este "balance con inventario" indagó sobre los desarrollos que, dentro del marxismo, atendieron especialmente a la pregunta sobre qué son los sindicatos. Lejos de las interpretaciones institucionalistas, especialmente de las que se acercaron al conflicto obrero expresado a través de estas organizaciones con la intención de desarrollar un management para evitarlo, se pudieron identificar las respuestas principales que produjo esa pregunta en distintos momentos de producción de esta corriente (aunque no se consideró por cuestiones de extensión, variantes como las que pueden leerse en el estructuralismo francés -Althusser y Poulantzas- o en el "sindicalismo revolucionario" de Sorel; ni las influencias del maoísmo en los autores franceses como más allá de ellos). ${ }^{20}$

Aquí se analizaron, en primer lugar, las obras de Marx y Engels sobre los sindicatos, señalando que las mismas evidencian una concepción no sistemática. En ella primó la interpretación de los sindicatos como "escuelas de guerra" y como herramienta para la toma de conciencia proletaria sobre la necesidad de una lucha de clase contra clase para organizar un nuevo orden social. Sin embargo, como pudo verse en la primera parte de este trabajo, no escapó a Marx ni a Engels que dentro de las asociaciones obreras floreció tempranamente una conciencia reformista que entendió como prioritaria la defensa de los intereses sectoriales o corporativos antes que la lucha internacionalista por el comunismo.

Por eso y desde el punto de vista aquí adoptado el conjunto de textos que dejaron los clásicos, tanto por su producción como por los contextos en que fueron publicados, no son suficientes para hablar de una teoría marxista sobre las organizaciones obreras. Se presenta de hecho como más adecuada la interpretación propuesta por Kelly, que destaca que hay suficiente evidencia -en los propios escritos y comparando la profundidad y sistematicidad de los mismos con otros trabajos de estos autores- que Marx y Engels nunca desarrollaron "una teoría" coherente y rigurosa sobre el sindicalismo.

Además, en una lectura con sutiles diferencias frente a la aquí ofrecida, Kelly sostiene que superando un inicial determinismo economicista Marx y Engels no tuvieron en realidad un deslizamiento desde posiciones "optimistas" sobre los sindicatos hacia unas más críticas o "pesimistas", sino que sus oscilaciones estuvieron asociadas e influenciadas con los ciclos de conflictos de clase de los que fueron testigos (1988, pp. 17-24). Esas oscilaciones prueban aún más la carencia de una teoría que les hubiera permitido seguir una línea de análisis más consistente a pesar de los cambios coyunturales en la política y la situación económica europea. ${ }^{21}$

Por eso se puede afirmar que en el marco de una comprensión única y pormenorizada de la naciente sociedad capitalista y del lugar que en ella tenía el trabajo asalariado, Marx y Engels sentaron las bases para desarrollar una teoría materialista sobre las organizaciones de la clase obrera y el hecho de que no hayan sistematizado sus ideas no significó ni significa que no pueda construirse una teoría marxista de los mismos, o sea una concepción de estas organizaciones que se derive y mantenga coherencia con la visión general sobre el capitalismo que estos aportaron.

Pero esa tarea, tal como está enunciada aquí, no fue una preocupación central de la generación de teóricos marxistas que los sucedió. Los marxistas apostados en el umbral del siglo veinte profundizaron el examen sobre estas organizaciones distinguiendo a los sindicatos de las organizaciones revolucionarias y poniendo bajo análisis en qué situaciones unas podrían confluir con las otras, y cómo se desarrollaría una conciencia revolucionaria que ya no estaba "determinada" por las condiciones objetivas de la producción capitalista 
ni se produciría en forma mecánica. Dentro de este conjunto de teóricos que hemos llamado "la segunda generación” señalamos el especial interés que tiene el aporte de Gramsci, sin desconocer que las suyas fueron circunstancias personales y políticas muy particulares, en especial si se lo compara con el núcleo bolchevique.

Es clave destacar que Gramsci comprendió a los sindicatos como instituciones propias del capitalismo, determinadas por las condiciones generales de esta organización social y no por una voluntad inherente a la clase trabajadora como conjunto. Cuestionando esto, Gramsci reconoció en los sindicatos a asociaciones de trabajadores con intereses particulares, no generales, y le asignó un rol clave a la negociación en la configuración y sostenimiento de estos sindicatos distanciándose de las calificaciones que guardaban para algún sindicalismo "verdadero" el rol de representante de la clase en su conjunto. Por el contrario, Gramsci indicó que la negociación establecía de facto una presión por la previsibilidad y la "respetabilidad" de los sindicatos, que restringía enormemente su capacidad de acción hasta el punto de sofocarlos.

Es en el desarrollo de esa línea de pensamiento que aquí se recupera la obra de R. Hyman, centralmente su concepción sobre la conformación social e históricamente determinada de los sindicatos, que retomando a Gramsci los entiende como asociaciones de fracciones de la clase cuya identificación común proviene, mayoritariamente, del lugar que ocupan como vendedores de fuerza de trabajo. En este mismo sentido hemos valorado la comprensión que Hyman sistematizó de los sindicatos como instituciones que funcionan en base a un doble sistema de control, que ejercen y sobre los que se ejercen presiones externas e internas que determinan sus objetivos y prácticas cotidianas en un contexto histórico concreto. Esta concepción estaba enraizada en la comprensión de que la venta de fuerza de trabajo no es la venta de una mercancía como cualquier otra, y que este hecho es tanto verdad para el comprador de esa fuerza de trabajo como para quienes son sus representantes en el mercado laboral.

A pesar de estos aportes, ni Hyman ni la escuela revolucionaria inglesa en los estudios del trabajo avanzó teóricamente, y el resultado de aquellos debates no resultó en una sistematización mayor. El marxismo fue quizás más próspero analizando otros aspectos de la relación capital-trabajo (como los que hacen a la teoría del Estado, el estudio de los procesos de trabajo, las teorías del conflicto y de la acción colectiva) que reflexionando sobre los desafíos que presenta el análisis de esta forma de organización política de la clase obrera tal como se dio a lo largo del siglo XX. Por esto, en la producción teórica sobre los sindicatos son solo algunos elementos específicos los que tienen filiación y vínculo orgánico con el corpus teórico marxista (tal como por ejemplo la concepción de fuerza de trabajo o de antagonismo) y otros a pesar de su relevancia mantienen una relación más distante, o son complementados por otras perspectivas (como la teoría de la regulación o la acción colectiva). En suma, un desarrollo integrado y consistente sobre los sindicatos sigue siendo una tarea pendiente, una tarea que requiere necesariamente de avanzar en la formulación de una comprensión dialéctica de las posibilidades, condicionantes y limites que el capital impone a las formas de organización de la clase obrera.

\section{Bibliografía}

Anderson, P. (1967). "The Limits and Possibilities of Trade Union Action". En Robin Blackburn y Alexander Cockburn(Eds.), The Incompatibles: trade union militancy and the consensus. London: Penguin.

Anderson, P. (1998). Consideraciones sobre el marxismo occidental [Traducido por Néstor Míguez]. Teoría. México: Siglo XXI.

Aris, R. (1998). Trade unions and the management of industrial conflict. Basingstoke: Macmillan.

Atzeni, M. (2016). Capitalism, Workers Organising and the Shifting Meanings of Workplace Democracy. Labor History Labor History 57(3), 374-89.

Basualdo, V., Löbbe, H., Colombo G., Pérez Álvarez, G.,Varela, P., Raimundo, M., ..., Scodeller, G. (2010). «Dossier: Hacia un debate sobre el concepto de "burocracia sindical"». Nuevo Topo, n.o7. 
Bensaïd, D. (2003). Marx intempestivo: grandeza y miserias de una aventura critica [Traducido por Agustín del Moral Tejeda]. Buenos Aires: Herramienta.

Brown, H. P. (1986). The Origins of Trade Union Power. Oxford: Oxford University Press.

Burawoy, M. (1979). Manufacturing consent: changes in the labor process under monopoly capitalism. Chicago: The University of Chicago Press.

Burgess, K. (1975). The origins of British industrial relations: the nineteenth century experience. Croom Helm social history series. London: Croom Helm.

Burgess, K. (1980). The Challenge of Labour: Shaping British Society, 1850-1930. New York: St. Martin’s Press.

Burgmann, V. (2016). Globalization and Labour in the Twenty-First Century. Routledge.

Ceruso, D.; Varela, P.; Zorzoli, L., Molinaro, L.; Gordillo, M., Haidar, J.(2016). Dossier: Burocracia sindical: de la dictadura al kirchnerismo. Revista Archivos de Historia del Movimiento Obrero y la Izquierda IV (8).

Cliff, T. (1983). Rosa Luxemburg. London: Bookmarks.

Cospito, G. (2017). Rhythm of Thought in Gramsci: A Diachronic Interpretation of Prison Notebooks. Haymarket Books.

Darlington, R. (1994). The Dynamics of Workplace Unionism: Shop Stewards Organization in Three Merseyside Plants. New York: Mansell.

Darlington, R. (2002). Shop Stewards' Leadership, Left-Wing Activism and Collective Workplace Union Organisation. Capital \& Class, 26(1), 95-126.

Duménil, G., y Dominique L. (2005). The Neoliberal (Counter) Revolution. En Alfredo Saad-Filho y Deborah Johnston (Eds.), Neoliberalism a Critical Reader. London: Pluto Press.

Engels, F. (1968). The Condition of the Working Class in England. Stanford, Calif.: Stanford University Press.

Farnham, D. (2008). Beatrice and Sidney Webb and the Intellectual Origins of British Industrial Relations. Employee Relations, 30(5), 534-52.

Frege, C., John K., y McGovern P. (2011). Richard Hyman: Marxism, Trade Unionism and Comparative Employment Relations: Richard Hyman. British Journal of Industrial Relations, 49(2), 209-30.

Gall, G. (2012). Richard Hyman: An assessment of his Industrial Relations: A Marxist Introduction. Capital \& Class, 36(1), 135-49. https://doi.org/10.1177/0309816811431874.

Gramsci, A. (12 de julio de 1919). La conquista del Estado. L'Ordine Nuovo.

Haidar, J. (2010). Gramsci y los consejos de fábrica: Discusiones sobre el potencial revolucionario del sindicalismo. Trabajo y sociedad, 15, 71-91.

Harvey, D. (1995). Globalization in Question. Rethinking Marxism Rethinking Marxism, 8(4), 1-17.

Hinton, J. (1973). The First Shop Stewards' Movement. London: G. Allen \& Unwin.

Hobsbawm, E. (1980). Historia del marxismo. Barcelona: Bruguera.

Hobsbawm, E. (1983). Marxismo e historia social. Instituto de Ciencias de la Universidad Autónoma de Puebla.

Holton, B. (1976). British syndicalism, 1900-1914: myths and realities. London: Pluto Press.

Hyman, R. (1971). The Workers' Union. Oxford: Clarendon Press.

Hyman, R. (1973). Marxism and the Sociology of Trade Unionism. London: Pluto Press.

Hyman, R. (1975). Industrial relations: A Marxist introduction. London: Macmillan.

Hyman, R. (1979). The Politics of Workplace Trade Unionism: Recent Tendencies and Some Problems for Theory. Berlin: International Institute for Comparative Social Research.

Kelly, J. E. (1988). Trade Unions and Socialist Politics. London; New York: Verso.

Kelly, J. E. (2002). The Field of Industrial Relations. En Rethinking Industrial Relations Mobilization, Collectivism and Long Waves (pp. 4-24). London; New York: Routledge.

Landreth, H., Colander D. C., y Rabasco, E. (2006). Historia del pensamiento económico. Madrid: McGraw-Hill. 
Lenguita, P., y Varela, P. (2010). Una reflexión sobre el rol de las comisiones internas en el sindicalismo argentino. En Claudia Figari, Paula Lenguita, y Juan Montes Cató(Eds.), El movimiento obrero en disputa. La organización colectiva de los trabajadores, su lucha y resistencia en la Argentina del siglo XX. Ediciones Ciccus-CEIL PIETTE.

Lenin, V. (2007). ¿Qué hacer? Problemas candentes de nuestro movimiento. Buenos Aires: Ediciones Luxemburg. Linden, M. van der. (2008). Workers of the World: Essays toward a Global Labor History. Leiden; Boston: Brill.

Lozovski, S. A. (1935). Marx and the Unions. Londres.

Lozovski, S. A. (1969). Marx y los sindicatos. México: Grijalbo.

Luxemburg, R. (1970). Huelga de masas, partido y sindicatos. México: Grijalbo.

Mandel, E. (1977). Control obrero, consejos obreros, autogestión. México, D.F.: Ediciones Era.

Mandel, E.(1985). «El capital»: cien años de controversias en torno a la obra de Karl Marx. México, D.F.: Siglo Veintiuno Editores.

Martinez, L. M. (2012). Union politics, purpose and democracy: To be or not to be? Optimism, pessimism and the continuing importance of Richard Hyman's early contributions. Capital \& Class, 36(1), 35-51.

Marx, K. (1987). Miseria de la filosofía: respuesta a la filosofía de la miseria de Proudhon [10.a ed]. México: Siglo Veintiuno.

Marx, K., y Engels, F. (1972). La ideología alemana: critica de la novisima filosofía alemana en las personas de sus representantes Feuerbach, B. Bauer y Stirner y del socialismo alemán en las de sus diferentes profetas. Montevideo; Barcelona: Ediciones Pueblos Unidos\#; Ediciones Grijalbo.

Marx, K., y Engels, F. (1975). Collected Works. New York: International Publishers.

Marx, K., y Engels, F. (1987). Marx and Engels on the Trade Unions. Editado por Kenneth Lapides. New York: Praeger.

Marx, K., Hobsbawm, E. J., Löwy, M., y Rossanda, R. (2003). El manifiesto comunista. Ensayos sobre su actualidad. Buenos Aires: Tesis 11.

McIlroy, J. (2012). Strikes and class consciousness in the early work of Richard Hyman. Capital \& Class, 36(1), 53-75. https://doi.org/10.1177/0309816811429738.

McLennan, G. (1981). Marxism and the Methodologies of History. London; New York: Verso.

Moody, K. (2014). In Solidarity: Essays on Working-Class Organization in the United States.

Moses, J. A. (1990). Trade Union Theory from Marx to Walesa. New York: Berg\#: Distributed exclusively in the US and Canada by St. Martin's Press.

Ness, I. (Ed.). (2014). New Forms of Worker Organization: The Syndicalist and Autonomist Restoration of Class Struggle Unionism. PM Press. Oakland, CA.

Offe, C., y Wiesenthal, H. (1995). «Two Logics of Collective Action». En Disorganized Capitalism: Contemporary Transformations of Work and Politics. Cambridge, Mass.: MIT Press.

Post, C. (2007). The "Labor Aristocracy". Solidarity, 128. https://www.solidarity-us.org.

Price, R. (1980). Masters, unions and men: work control in building and the rise of labor, 1830-1914. Cambridge: Cambridge University Press.

Santella, A. (2011). Un aporte al debate teórico sobre la burocracia sindical. Nuevo Topo, 8, 133-47.

Santella, A. (2014). ¿Qué son los sindicatos en la teoría marxista?. Revista Archivos de Historia del Movimiento Obrero y la Izquierda, 5 (septiembre).

Senén González, C., y Ghiotto L. (2008). Teoría, métodos y estudios en relaciones laborales. Un abordaje desde la disciplina. Revista ARTRA, 5.

Shepherd, J. S. (1980). The Lib-Labs and English Working Class Politics, 1874-1906. University of London.

Silver, B. J. (2003). Forces of Labor: Workers' Movements and Globalization since 1870. Cambridge; New York: Cambridge University Press.

Traverso, E., y Petrecca, M. A. (2009). A sangrey fuego: de la guerra civil europea, 1914-1945. Buenos Aires: Prometeo. 
Trotsky, L. (1973). Programa de transición para la revolución socialista. [Traducido por Daniel Sadunaisky]. Buenos Aires: Pluma.

Trotsky, L. (2007). La revolución permanente. [Traducido por Andreu Nin]. Buenos Aires: Libros de Anarres.

VVAA. (2010). Dossier: Hacia un debate sobre el concepto de "burocracia sindical". Nuevo Topo, 7.

VVAA. (2016). Dossier: Burocracia sindical: de la dictadura al kirchnerismo. Revista Archivos de Historia del Movimiento Obrero y la Izquierda, $I V(8)$.

Womack, J. (2007). Posición estratégica y fuerza obrera: hacia una nueva historia de los movimientos obreros. [Traducido por Lucrecia Orensanz] Escofet. México: Fondo de Cultura Económica.

Wood, S. (1976). The Radicalisation of Industrial Relations Theory. Personnel Review, 5(3), 52-57. https://doi.org/ $10.1108 / \mathrm{eb} 055317$.

Wright, E. O. (1997). Class Counts: Comparative Studies in Class Analysis. Cambridge; New York; Paris: Cambridge University Press\#; Maison des Sciences de l'homme.

Wright, E. O. (2000). Working-class power, capitalist-class interests, and class compromise. American Journal of Sociology, 957-1002.

Zorzoli, L. (2014). Para pensar las prácticas sindicales. Una lectura de la sentencia por el asesinato de Mariano Ferreyra. Conflicto Social, 7(11), 31-66.

Zorzoli, L. (2017). Consideraciones sobre el modelo sindical argentino a la luz de la propuesta de Richard Hyman. Revista Latinoamericana de Estudios del Trabajo, 21(34), e.

\section{Notas}

1 Quisiera expresar aquí mi agradecimiento a los evaluadores y a Juan Pedro Massano y Juan Grigera por el intercambio y las sugerencias que me permitieron enriquecer este trabajo.

2 Esta propuesta tiene preocupaciones similares con un artículo reciente de Santella, aunque en él se busca identificar solo las concepciones principales del marxismo clásico para vincularlas con una investigación empírica sobre los modos de movilización de las y los trabajadores en Argentina. Ver Santella (2014).

3 Esas asociaciones obreras eran secretas y clandestinas en un principio, y se convirtieron en legales en Inglaterra recién a partir de 1824 por una ley de la Cámara de los Comunes. Sin embargo su status fue fluctuante por un período mucho más extenso. Sobre la historia y desarrollo de los sindicatos en Inglaterra, considerados precursores del sindicalismo moderno, ver entre otros Hinton (1973) y Burgess (1980).

4 Si no se consigna indicación en contrario, las traducciones del inglés son propias.

5 Dice Engels: "Estas huelgas, que comienzan como escaramuzas, y resultan a veces en importantes luchas; no cambian nada, es cierto. Pero son la prueba más cierta de que se aproxima la batalla decisiva entre el proletariado y la burguesía. Son la escuela de guerra de los obreros, donde se preparan para el gran combate inevitable; son los pronunciamientos de diferentes ramas del trabajo, consagrando su adhesión al movimiento obrero" (Marx y Engels, 1975,Vol. 4, pp. 513-514).

6 Un desarrollo de estas ideas puede verse en la propuesta de David Harvey (1995) y de Beverly Silver (2003) sobre el "spatialfix", "productfix" y "financialfix", que son centrales para entender la revolución neoliberal al decir de Duménil y Lévy (2005).

7 En su trabajo sobre los sindicatos en las obras de Marx y Engels, K. Lapides considera estos, junto con algunos extractos de La ideología alemana (Marx y Engels, 1972) y escritos periodísticos en The Northen Start o en la serie sobre trabajo asalariado y capital publicada incompleta en el periódico Neue Rheinische Zeitung (1849), que fueran luego editadas completas en ruso en 1924 y en inglés en 1976 (Marx y Engels, 1987, 3-37, 181). Sobre esta última Moses realiza un detallado análisis. Ver Moses («Wages, Price and Profit», 1990, pp. 33-43). Se ha optado por usar estas dos obras como guías y no el trabajo de Lozovski, que consideramos menos sistemático (1935, existe traducción al castellano, ver 1969)

8 Moses señala cómo algunos pasajes del Manifiesto Comunista han dado lugar, por su sintética y simplificada presentación, a distintas interpretaciones, que lamentablemente no pueden ser abordadas aquí (sobre ellas ver Moses, 1990, p. 23). Otros debates y lecturas actuales del Manifiesto Comunista pueden encontrarse en El manifiesto comunista. Ensayos sobre su actualidad (Marx et al., 2003) en el que se encuentran trabajos de E. J. Hobsbawm, Michael Löwy, y Rossana Rossanda al respecto.

9 Es en estos escritos en que ambos autores se distancian y responden a las visiones propuestas por el anarquismo sobre los sindicatos. Sobre esto puede verse Moses, "Marx and Engels against anarchism and anarcho-syndicalism” (1990, pp. 51-58). 
10 Sobre los Lib-labs y su significación en la política de clase obrera británica a finales del siglo XIX puede verse Shepherd (1980).

11 Es por esa misma razón que Kelly señala que Gramsci sí dejó un “conjunto coherente de trabajos sobre los sindicatos” que permaneció sin embargo relativamente subestimado dentro del marxismo.

12 Para los Webbs, que marcaron fuertemente los desarrollos posteriores no marxistas, un sindicato era una asociación estable de asalariados reunidos con el propósito de mantener o mejorar sus condiciones de vida. Reconocían sin embargo que para cumplir con ese objetivo los sindicatos podían darse más de una estrategia: establecer de antemano en qué condiciones sus miembros venderían su fuerza de trabajo, negociar esas condiciones con los empleadores o presionar a los poderes políticos para que estableciera leyes generales de protección (Farnham, 2008).

13 Suelen señalarse como los miembros de la "escuela revolucionaria" en los estudios del trabajo en Inglaterra a James Hinton (a partir especialmente de su obra "Thefirst shop steward'smovement" de 1973); a Richard Price por su obra "Masters, unions and men: work control in building and rise of labor 1830-1914" (1980); a John Burgess (por "Theorigins of British industrial relations: the nineteenth century experience" en 1975); a Bob Holtonpor "British syndicalism" (1976) y a Richard Hyman (por trabajos como "Theworkers union" de 1971, "Marxism and thesociology of tradeunionism" de 1973, o "Industrial relations a Marxist introduction", de 1975).

14 Zorzoli (2017). Ver también Senén González y Ghiotto (2008), Frege, Kelly y McGoven (2011), Gall (2012), McIlroy (2012) y Martínez Lucio (2012).

15 Sobre este punto ver las conclusiones que presenta en su trabajo “Theworkers” unión” (Hyman, 1971).

$16 \mathrm{El}$ rol del consentimiento en la producción fue también profusamente abordado. Véase, como ejemplo, el trabajo pionero de Michael Burawoy Manufacturing consent changes in the labor process under monopoly capitalism (1979).

17 Un debate nacional al respecto puede verse en los dossier de las revistas Nuevo Topo (VVAA, 2010) y Archivos de Historia del movimiento obrero y la izquierda (VVAA, 2016). Ver también Santella (2011).

18 Debe tenerse en cuenta el sesgo antiteórico y descriptivo de los estudios laborales en general y los anglosajones en particular. Para un estado de la cuestión sobre este campo de estudios ver Kelly (2002).

19 La idea de que la posibilidad / amenaza de la huelga como fundante del poder sindical lejos está de ser exclusiva de este trabajo. Ver entre otros Offe y Wiesenthal (1995) o Brown (1986).

20 Tampoco se tratan en este artículo los desarrollos del marxismo italiano post Gramsci, ni de los cambios que él mismo realiza en su concepción del tema en los Cuadernos de la Cárcel según Cospito (2017). Un estudio que contemple el tratamiento hecho por estas y otras corrientes del marxismo occidental del siglo XX es una tarea pendiente.

21 Esto no implicó para Kelly que las posiciones de Marx y Engels oscilaran entre dos extremos sin que mediaran cambios. Por el contrario, indica que "a lo largo de sus vidas avanzaron gradualmente hacia la idea de que la aparición del sindicalismo no revolucionario y la política reformista no eran un desarrollo anormal, un subproducto del imperialismo británico y por lo tanto un fenómeno único de la sociedad británica, sino una poderosa forma de sindicalismo y de política creada y sostenida por una variedad de factores políticos y económicos” (Kelly, 1988, p. 25) 